\title{
The Cooperative Revolution Reaches Clinical Psychology and Psychotherapy: An Example From Germany
}

\author{
Jürgen Margraf $^{\mathrm{a}}(\mathbb{D})$, Jürgen Hoyer ${ }^{\mathrm{b}}$, Thomas Fydrich ${ }^{\mathrm{c}}$, Tina In-Albon ${ }^{\mathrm{d}}$, Tania Lincoln ${ }^{\mathrm{e}}$, \\ Wolfgang Lutz ${ }^{\mathrm{f}}$, Angelika Schlarb ${ }^{\mathrm{g}}$, Henning Schöttke ${ }^{\mathrm{h}}$, Ulrike Willutzki ${ }^{\mathrm{i}}$, Julia Velten ${ }^{\mathrm{a}}$
}

[a] Mental Health Research and Treatment Center, Ruhr University Bochum, Bochum, Germany. [b] Clinical Psychology and Psychotherapy, Technical University of Dresden, Dresden, Germany. [c] Department of Psychology, HumboldtUniversität zu Berlin, Berlin, Germany. [d] Clinical Child and Adolescent Psychology and Psychotherapy, University of Koblenz-Landau, Landau, Germany. [e] Clinical Psychology and Psychotherapy, Universität Hamburg, Hamburg, Germany. [f] Clinical Psychology and Psychotherapy, Trier University, Trier, Germany. [g] Clinic Psychology and Psychotherapy of Children and Adolescents, Bielefeld University, Bielefeld, Germany. [h] Clinical Psychology and Psychotherapy, Osnabrück University, Osnabrück, Germany. [i] Clinical Psychology and Psychotherapy, University Witten/Herdecke, Witten, Germany.

Clinical Psychology in Europe, 2021, Vol. 3(1), Article e4459, https://doi.org/10.32872/cpe.4459

Received: 2020-09-25 • Accepted: 2020-12-30 • Published (VoR): 2021-03-10

Handling Editor: Winfried Rief, Philipps-University of Marburg, Marburg, Germany

Corresponding Author: Jürgen Margraf, Mental Health Research and Treatment Center, Ruhr University Bochum, Massenbergstrasse 9-13, Bochum, D-44787, Germany. Tel: +492343223169. Fax: +492343203169. E-mail: juergen.margraf@rub.de

Supplementary Materials: Materials [see Index of Supplementary Materials]

\begin{abstract}
Background: Psychology is at the beginning of a cooperative revolution. Traditionally, psychological research has been conducted by individual labs, limiting its scope in clinical samples and promoting replication problems. Large-scale collaborations create new opportunities for highly powered studies in this resource-intensive research area. To present the current state of a Germany-wide platform for coordinating research across university outpatient clinics for psychotherapy.

Method: Since 1999, over 50 such clinics were created in Germany. They represent a unique infrastructure for research, training, and clinical care. In 2013, a steering committee initiated a nationwide research platform for systematic coordination of research in these clinics (German abbreviation "KODAP"). Its main goal is to aggregate and analyze longitudinal treatment data including patient, therapist, and treatment characteristics - across all participating clinics.
\end{abstract}


Results: An initial survey (100\% response rate) yielded recommendations for improved integration of data collection. Pilot data from 4,504 adult (16 clinics) and 568 child and adolescent patients (7 clinics) proved feasibility of data transfer and aggregation despite different data formats. Affective, neurotic, stress, and somatoform (adults) and anxiety and behavioral (children and adolescents) disorders were most frequent; comorbidity was high. Overcoming legal, methodological, and technical challenges, a common core assessment battery was developed, and data collection started in 2018. To date, 42 clinics have joined.

Conclusions: KODAP shows that research collaboration across university outpatient clinics is feasible. Fulfilling the need for stronger cumulative and cooperative research in Clinical Psychology will contribute to better knowledge about mental health, a core challenge to modern societies.

\section{Keywords}

psychotherapy research, outpatient clinics, collaborative research, replication crisis

\section{Highlights}

- Data from 4,504 adult and 568 child and adolescent patients were successfully aggregated across 23 outpatient clinics.

- Affective, neurotic, stress, and somatoform (adults) and anxiety and behavioral (children and adolescents) disorders were most frequent; comorbidity was high.

- Legal, methodological, and technical challenges were overcome, and a common core assessment battery was developed.

- 42 clinics have joined a Germany-wide research platform for systematic coordination of research in these clinics. Longitudinal data collection started in 2018.

Psychology and psychotherapy are at the beginning of a cooperative revolution (Chartier et al., 2018; Spellman, 2015). Traditionally, research in these fields has been conducted by individual labs, limiting its scope in clinical samples and promoting replication problems. In response to the so-called "replication crisis" in medicine, psychology and related fields (Camerer et al., 2018; Dumas-Mallet et al., 2017; Ioannidis, 2005; Open Science Collaboration, 2015; Pashler \& Wagenmakers, 2012), the search for causes revealed methodological issues including insufficient sample sizes (Button et al., 2013; Flint et al., 2015; Rossi, 1990; Simmons et al., 2011) and the "file drawer problem" (aka publication bias; Kirsch et al., 2002; Rosenthal, 1979; Turner et al., 2008). These proximal causes are worsened by misaligned incentives in a context of dwindling research funding and increasing pressure to publish or perish (Margraf, 2015; Spellman, 2015). In addition, basic aspects of our academic cultures may serve as major contributors to the crisis by accelerating a race that, under the motto "winner takes all", favors fundamentally undesirable developments (Fang \& Casadevall, 2012b). These "cultural" aspects include an exaggerated cult of originality (Fang \& Casadevall, 2012a) and the "toothbrush problem" (Mischel, 2008): We 
tend to treat other peoples' theories like toothbrushes - every decent person uses one but no self-respecting person wants to use anyone else's. If getting and keeping your job and status requires achieving "originality" by not building on anyone else's work, it may directly undermine the goal of building a cumulative science (Mischel, 2008). The conflict applies not only to theories but also to therapies: The field is full of overstated claims of originality and uniqueness, leading to ill-founded distinctions and misguided competition that impede fruitful cooperation. As a result of this "disconnect between what is good for scientists and what is good for science" (Nosek et al., 2012, p. 616) we have a situation, where "most published research findings are false" (Ioannidis, 2005) and "most clinical research is not useful" (Ioannidis, 2016).

We cannot, however, simply deplore external pressures and individual misconduct, we must also devote our critical attention to the cult of originality and priority and the overemphasis on individual contributions that underlie them. We need to pursue an academic community that works collectively, albeit competitively, to advance theory and therapy. This requires developing common shared tools and a more serious quest for robust, replicable and consequential findings (Mischel, 2009). The importance of teamwork in science has never been greater (Fang \& Casadevall, 2012a). Teams increasingly dominate science and are contributing the highest-impact and most reliable research. Collaborations, consortia and networks are essential for tackling many of the most important challenges in psychotherapy and psychosomatics. Luckily, scientists in psychology and medicine recently have opened up much more to new forms of increased collaboration, allowing them to initiate projects at a scale previously unattained. Perhaps the most visible hallmark of the cooperative revolution has been the rapid increase in large-scale collaborations such as ManyLabs, ManyBabies, Open Science Collaboration, Psychological Science Accelerator, Registered Replication Reports, and StudySwap (Chartier et al., 2018). Our research questions as well as our often still inadequate measurement accuracy typically require very large samples (Margraf, 2015). Large joint projects and individual projects coordinated with them must complement each other, and the necessary infrastructure must be developed. This should create new opportunities for highly powered studies even in resource-intensive areas such as psychotherapy research.

The present article describes the example of an innovative approach to collaborative psychotherapy research from Germany (Hoyer et al., 2015; In-Albon et al., 2019; Velten et al., 2017, 2018). Since Germany established the legal basis for psychotherapy outpatient clinics at university departments of Clinical Psychology in 1999, over 50 such clinics devoted to research (i.e., research clinics) and to clinical training of psychotherapists (i.e., training clinics) were created. Each year, many thousand patients across all age and clinical groups are treated under routine clinical conditions as well as in circumscribed research projects (In-Albon et al., 2019; Velten et al., 2018). Together, they represent a unique infrastructure for research, training and clinical care that rapidly has proven to be an important facilitator of research in psychotherapy and mental health. The clinics 
routinely gather a large amount of data on therapy outcomes as well as on patient and therapist characteristics (Velten et al., 2017). High standards of quality assurance are achieved in these outpatient clinics through regular, standardized diagnostic assessments. These data can also be used for research, in particular psychotherapy research (e.g., Ziem \& Hoyer, 2020). In spite of this remarkable track record, the full potential of synergetic gain from a systematic coordination of research at the clinics had until recently not yet been sufficiently exploited. The scientific evaluation of treatment data is particularly difficult for clinics with a smaller number of cases: Patients and therapists often invest time and effort to answer questions about symptoms, the course of therapy or therapeutic relationships without sufficiently large samples for quantitative analysis. Up to now, the combination of the collected data with other clinics has been an exception that was limited to individual multicenter research projects (e.g., Gloster et al., 2011; Hoyer et al., 2016; Lutz et al., 2009). Nonetheless, the chances of an aggregation of research data across clinics are manifold.

Research coordination would involve a standardization in diagnostic documentation, a standardized reporting system and consequently the possibility of aggregating data from several or all outpatient clinics. Proposals for practice research networks have already been discussed on various occasions (e.g., Borkovec et al., 2001; Castonguay, 2011). A collaborative approach offers a number of important advantages: With the aggregated basic data, research with a large number of cases can be carried out in a short time. If necessary, comparatively rare disorders or their variants (e.g., Skin Picking Disorder, Depersonalization/Derealization Disorder, Sexual Dysfunctions; Balon, 2017; Sierra \& David, 2011; Velten et al., 2021) even those not yet explicitly defined in classification systems (e.g. Facebook Addiction Disorder; Brailovskaia et al., 2018, 2019) can be investigated. In the case of more frequent disorders, the high number of cases allows subgroup comparisons and valid benchmark analyses to be carried out. Current topics such as the investigation of therapist data, discontinuation rates, the hotly debated topic of failures and side effects (Jacobi et al., 2011), transgenerational psychotherapy effects (Schneider et al., 2013) or groundbreaking developments in basic research (such as in the area of therapygenetics; Coleman et al., 2017; Rayner et al., 2019; Roberts et al., 2017, 2019; Wannemüller et al., 2018a; Wannemüller et al., 2018b) could be addressed more quickly with highly visible studies based on large clinical data sets. Ultimately, the collaborative database provides a valuable starting point for applying for major projects.

In 2013, an initiative group began to lay the groundwork for the systematic coordination of research in the German university outpatient clinics for psychotherapy in order to create a nationwide research platform for clinical psychology and psychotherapy (German abbreviation "KODAP" for "Coordination of Data Acquisition at Research Clinics for Psychotherapy”). This platform will allow the aggregation and analysis of longitudinal treatment data - including patient, therapist, and treatment characteristics - across all participating clinics for adults, children and adolescents. The short-term goal 
of KODAP was to establish the feasibility of large-scale coordinated research. Medium to long-term goals of the project are the advancement of theory, practice, and dissemination of psychotherapy and clinical psychology. The present article describes the steps taken, the challenges that had to be overcome and four feasibility studies that were carried out.

\section{Overview of Feasibility Studies}

Immediate goals of Study 1 (Hoyer et al., 2015) were (a) to gather information on the core characteristics of the clinics and on this basis (b) to develop proposals for better integration of research efforts. In order to estimate the size and clinical composition of potential populations for future studies the number of patients initiating treatment in the participating KODAP outpatient clinics in 2016 as well as their diagnoses and psychopathological complaints together with the database, research and administrative software used in the clinics were recorded. Immediate goals of Study 2 (Velten et al., 2017) were (a) to develop a comprehensive catalogue of the considerable logistical, technical and legal data protection challenges facing the planned research collaboration, (b) to use this to examine the workability of cross-clinic collection of patient, therapist and therapy data and (c) to plan the third and fourth pilot studies. Study 3 (Velten et al., 2018) and Study 4 (In-Albon et al., 2019) aimed (a) to actually aggregate patient data across a pilot sample of clinics (Study 3: adults, Study 4: children and adolescents) treated in 2016 and use this (b) to test all the processes necessary for data preparation, transmission and aggregation at the cooperation partners and the central coordination center. The focus was on the frequency distribution of treatment diagnoses to answer the following research questions: Which disorders are frequently treated, which are rarely? How high is the proportion of severely distressed patient groups with more than one disorder diagnosis, at least one personality disorder or severe symptoms?

\section{Study 1 (Hoyer et al., 2015)}

\section{Method}

A complete list of outpatient clinics at German university departments of clinical psychology and psychotherapy for the psychotherapeutic treatment of adults, children and adolescents (referred to as "clinics" in the following) was compiled in 2014 (Hoyer et al., 2015). This yielded 53 institutions whose scientific and managing directors were contacted by e-mail in May 2014 with the request to complete a short survey form. A questionnaire was developed by the initiative group to record the characteristics of the clinics. It asked for the diagnostic instruments, disorder-specific and general clinical questionnaires, as well as the patient and therapist variables of interest. In addition, the type, strengths and weaknesses of the clinical, research and administrative software used was assessed by open questions. Finally, the clinics reported the annual number of pre 
and post therapy datasets of all patients (i.e., defined as any person for whom a patient file was created) treated in 2013. Case numbers for adults and children and adolescents were asked separately.

\section{Results}

All 53 clinics contacted provided data on their institution by November 2014 (100\% response rate). Whereas some of the clinics were still in the planning or construction stage or could not provide reliable data on current patient numbers for technical reasons, 49 clinics were able to provide information on their annual number of patients. Estimates (some of the clinics were able to provide only approximate data) for patients treated in 2013 yielded 8200 pre- and 5400 post-therapy data records for adults, and 2400 pre- and 1100 post-therapy data records for children and adolescents.

There were clear overlaps in the methods used for the diagnosis of mental disorders as shown in Table 1. Given the large number of different mental disorders treated in the clinics, it is not surprising that more than 150 different disorder-specific instruments were identified by the survey.

\section{Table 1}

Diagnostic Assessments Utilized Routinely in Outpatient Clinics (Instruments Used by at Least 15\% of Clinics).

\begin{tabular}{|c|c|}
\hline Instrument & $\begin{array}{c}\text { \% of clinics using } \\
\text { instrument }\end{array}$ \\
\hline \multicolumn{2}{|l|}{ Instruments used for ICD/DSM diagnoses } \\
\hline \multicolumn{2}{|l|}{ Adults } \\
\hline Structured Clinical Interview for DSM-IV ${ }^{\mathrm{a}}$, SCID & 89.2 \\
\hline International Diagnostic Checklist ${ }^{\mathrm{b}}$, IDCL & 21.6 \\
\hline Diagnostic Interview for Mental Disorders ${ }^{\mathrm{c}}$, DIPS & 16.2 \\
\hline \multicolumn{2}{|l|}{ Children and adolescents } \\
\hline Diagnostic Interview for Mental Disorders in Childhood and Adolescence ${ }^{\mathrm{d}}$, Kinder-DIPS & 85.7 \\
\hline
\end{tabular}

General clinical instruments

\section{Adults}

Brief Symptom Inventory ${ }^{\mathrm{e}}$, BSI $\quad 62.2$

Symptom Checklist 90-Revised ${ }^{\mathrm{f}}$, SCL 90-R $\quad 45.9$

Inventory of Interpersonal Problems ${ }^{\mathrm{g}}$, IIP $\quad 27.0$

Clinical Global Impressions Scale ${ }^{\mathrm{h}}$, CGI

\section{Children and adolescents}

Child Behavior Checklist ${ }^{\mathrm{i}}$, CBCL/6-18R $\quad 64.3$

Youth Self-Report of the Child Behavior Checklist ${ }^{\mathrm{i}}$, YSR/11-18R

Teacher Report Form ${ }^{\mathrm{i}}$, TRF/6-18R $\quad 50.0$

Inventory for the Assessment of Life Quality in Children and Adolescents ${ }^{\mathrm{j}}$, ILK $\quad 42.9$ 


\begin{tabular}{lc}
\hline Instrument & $\begin{array}{c}\text { of clinics using } \\
\text { instrument }\end{array}$ \\
\hline
\end{tabular}

Disorder-specific instruments

\begin{tabular}{|c|c|}
\hline \multicolumn{2}{|l|}{ Adults } \\
\hline Beck Depression Inventory ${ }^{\mathrm{k}}$, BDI I or BDI II & 89.2 \\
\hline Body Sensations Questionnaire, Agoraphobic Cognitions Questionnaire, Mobility Inventory ${ }^{1}$ & 64.9 \\
\hline Screening for Somatoform Symptoms $2^{\mathrm{m}}$, SOMS 2 & 56.8 \\
\hline Eating Disorder Inventory $2^{\mathrm{n}}$, EDI 2 & 48.6 \\
\hline Social Interaction Anxiety Scale ${ }^{\circ}$, SIAS & 48.6 \\
\hline Hamburg Obsessive/Compulsive Inventory ${ }^{\mathrm{p}}$, HZI & 45.9 \\
\hline Social Phobia-Scale ${ }^{\circ}$, SPS & 43.2 \\
\hline Posttraumatic Stress Diagnostic Scale ${ }^{\mathrm{q}}$, PSD & 40.5 \\
\hline Impact of Event Scale ${ }^{\mathrm{r}}$, IES & 35.1 \\
\hline Eating Inventory ${ }^{\mathrm{s}}, \mathrm{FEV}$ & 29.7 \\
\hline Borderline-Symptom-List-23 ${ }^{\mathrm{t}}$, BSL-23 & 29.7 \\
\hline Yale Brown Obsessive Compulsive Scale ${ }^{\mathrm{u}}$, Y-BOCS & 27.0 \\
\hline \multicolumn{2}{|l|}{ Children and adolescents } \\
\hline Children's Depression Inventory ${ }^{\mathrm{v}}$, DIKJ & 64.3 \\
\hline Fear Survey Schedule for Children - Revised ${ }^{\mathrm{w}}$, PHOKI & 57.1 \\
\hline Social Phobia and Anxiety Inventory for Children ${ }^{\mathrm{x}}$, SPAIK & 35.7 \\
\hline Anxiety Questionnaire for School Students ${ }^{\mathrm{y}}$, AFS & 35.7 \\
\hline
\end{tabular}

âWittchen et al., 1997. ' Hiller et al., 1997. ${ }^{\mathrm{c}}$ Margraf et al., 2017; Schneider \& Margraf, 2011. ${ }^{\mathrm{d}}$ Margraf et al., 2017; Schneider et al., 2009. 'Derogatis \& Spencer, 1993; Franke, 1997. fDerogatis, 1992; Franke \& Derogatis, 1995.

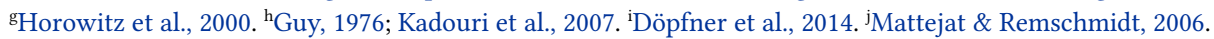

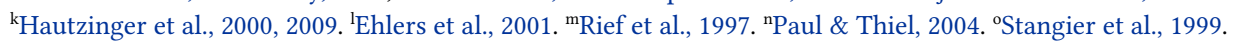

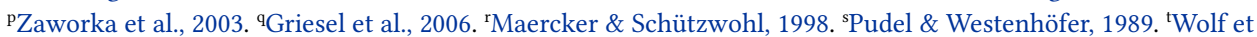

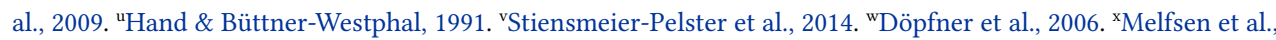
2001. ${ }^{\text {y} W i e c z e r k o w s k i ~ e t ~ a l ., ~} 1981$.

The systematic collection of essential patient characteristics such as age, gender and diagnosis (see Table 2) is a standard in all participating clinics. In addition, most clinics also record level of education, marital status and the number of therapy sessions. The documentation of therapist characteristics is limited to therapist gender, age and training status in most clinics. A large number of different software programs for patient data maintenance, room planning and billing as well as other administrative purposes are used by the clinics. These include programs from commercial providers as well as individual database solutions created in-house. The three most frequently cited software tools were PsychoEQ (PsychoWare Software), AMBOS (Therapy Organization Software) and self-developed SPSS or Microsoft Excel databases. The most frequently named strengths of the respective software solutions are their individual adaptability to the needs of the clinic, easy exportability of the data, simple operation and good support from the manufacturer. Frequently mentioned weaknesses of the programs are the susceptibility to errors, the limitation of data export only via employees of the manu- 
facturer as well as the missing possibility to record specific variables such as therapist characteristics.

Table 2

Patient and Therapist Characteristics Reported in Feasibility Study 1

\begin{tabular}{lc}
\hline Variable & \% of clinics giving information \\
\hline Patient characteristics & \\
Age & 100 \\
Gender & 100 \\
Diagnosis (ICD-10) & 100 \\
Level of education & 95.9 \\
Marital status & 93.9 \\
Number of treatment sessions & 93.9 \\
Index diagnosis & 89.8 \\
\hline Therapist characteristics & \\
Gender & 77.6 \\
Age & 69.4 \\
Training status (fully licensed vs. in training) & 65.3 \\
\hline
\end{tabular}

\section{Study 2 (Velten et al., 2017)}

\section{Method}

The results of the first pilot study were evaluated by the initiative group ${ }^{1}$ in several faceto-face meetings as well as in telephone and Skype conferences in 2015 and 2016. Two subgroups dealt with the variables for adults and for children/adolescents, respectively. This led to the following structure of the catalogue of logistical, technical and legal data protection challenges facing the planned research collaboration: (1) organizational framework conditions, (2) cooperation agreement, (3) Steering Group, (4) coordination center, (5) initial set of variables to be collected for adults and for children and adolescents, (6) process to expand the dataset in the future, (7) data protection of transmitted information and ethical approval, (8) planning of the final feasibility study (Velten et al., 2017). For each of these sections specific recommendations were formulated on the basis of unanimous decisions. In addition, the procedures for patient informed consent and ethical approval of the project had to be developed.

1) C. Bennecke, M. Berking, J. Hoyer, T. In-Albon, T. Lincoln, W. Lutz, J. Margraf, A. Schlarb, H. Schöttke, U. Willutzki. 


\section{Results}

Based on the results of Study 1, the initiative group for the development of research cooperation derived recommendations regarding the catalogue of challenges for the cooperation project listed below. All recommendations were formulated on the basis of unanimous decisions by the initiative group.

(1) Organizational framework conditions - The planned research cooperation requires a solid organizational basis that must be supported by a legal entity. On 20 March 2017, Unith.ev began to serve as the organizing institution of the KODAP project. Unith.ev (the network of German university outpatient clinics for psychotherapy) is a registered non-profit association (the German "ev" stands for registered association, "unith" combines "university" and "therapy"). The sponsorship by a registered association clarifies the continued legal responsibility, and the non-profit character underlines the non-commercial character of its research, which serves the common good.

(2) Cooperation agreement - In order to legally secure the ambitious project, a cooperation agreement was drafted which regulates the rights and obligations of all participating clinics. It specifies the subject matter of the contract and provides the relevant information on the duration, confidentiality, liability and termination of membership in the project. In order to ensure the effective execution of the scientific and operational work of the research network, a steering group and a coordination center had to be established. Their respective tasks are also defined in the cooperation agreement (in German language, available from the first author on request).

(3) Steering group - The tasks of the steering group include the development, support and conception of KODAP's research activities. At present (mid-2020), the steering group consists of most members of the initiative group, which was formed in October 2013 at the annual meeting of German university professors of clinical psychology and psychotherapy. So far, the group met about three times a year, addressing the essential steps of the project, taking decisions by consensus. It currently consists of 8 members, representing 8 different universities. Rules of procedure were adopted in January 2017 to govern the rights and duties of the steering group (in German language, available from the first author on request) and contain guidelines for publications based on KODAP data.

(4) Coordination center - The main tasks of the coordination center are the collection, storage, quality control, aggregation and statistical analysis of the data obtained. The data sets which the participating clinics provide annually for the KODAP project are aggregated and stored in the coordination center. This task was taken over by the Mental Health Research and Treatment Center of Ruhr University Bochum. Regular reports, 
which serve to keep the partners continuously informed about the progress of work, are prepared by the coordination center. The rights and duties of the coordination center are set out in the cooperation agreement (in German language, available from the first author on request).

(5) Initial set of variables - The initial core data set defined is presented in Table 3.

\section{Table 3}

Initial Core Set of Variables to be Collected for Adults and for Children and Adolescents

\section{Patient characteristics}

All

Age (years)

Gender

Previous psychological or psychosocial treatments

Index and additional diagnoses (ICD-10, before and after therapy) based on structured or standardized

clinical interviews

Level of education

Clinicians Global Impression Scale ${ }^{\mathrm{a}}$, CGI

\section{Adults}

Marital status

Brief Symptom Inventory ${ }^{\mathrm{b}}$, BSI or Symptom Checklist 90-Revised ${ }^{\mathrm{c}}$, SCL 90-R

Beck Depression Inventory ${ }^{\mathrm{d}}$, BDI I or BDI II

\section{Children and adolescents}

Child Behavior Checklist ${ }^{\mathrm{e}}$, CBCL

Youth Self-Report of the Child Behavior Checklist ${ }^{e}$, YSR 11-18R

Psychosocial stressors (max. 5)

Living situation

Parent variables: $\mathrm{BSI}^{\mathrm{b}}$ or SCL-90- $\mathrm{R}^{\mathrm{c}}$, level of education, partnership status

\section{Therapist characteristics}

Gender

Age

Training status (fully licensed vs. still in training)

\section{Treatment variables}

Number of therapy sessions

Type of treatment performed

Current treatment status (ongoing, discontinued, regular termination)

${ }^{\mathrm{a} G u y, ~ 1976 ; ~ K a d o u r i ~ e t ~ a l ., ~ 2007 . ~}{ }^{\mathrm{b} D e r o g a t i s ~ \& ~ S p e n c e r, ~ 1993 ; ~ F r a n k e, ~ 1997 . ~ ' D e r o g a t i s, ~ 1992 ; ~ F r a n k e ~ \& ~ D e r o g a t i s, ~}$ 1995. ${ }^{\text {H} H a u t z i n g e r ~ e t ~ a l ., ~ 2000, ~ 2009 . ~}{ }^{~ D o ̈ p f n e r ~ e t ~ a l ., ~} 2014$. 
The aim of assessing only a limited number of variables was to minimize the additional burden of data collection for KODAP and to allow clinics to continue using established assessments. Since the psychometric instruments are given before and after treatment, it is possible to evaluate therapy outcome.

All patient and therapist data are collected in pseudonymized form. Special consideration needs to be given to the problem of personal data, as is emphasized in Article 26 of the basic EU data protection regulation (see Regulation [EU] 2016/679; European Parliament and Council, 2016), which became effective in May 2018. KODAP follows the recommendations of a task force of the German Society of Psychology. As a consequence, the KODAP project does not collect data that are used in combination by a "person at his or her own discretion [...] to identify the natural person directly or indirectly" (Article 26). In order to ensure that individual patients - even those with rare disorders - cannot be identified on the basis of personal characteristics such as occupation or date of birth, only basic characteristics (level of education, age in years, gender, pre- and post-therapy diagnoses) are to be collected in the KODAP project. This procedure enables the storage of different data for a given patient over several years necessary for the longitudinal data collection, one of the central goals of KODAP. The same considerations also apply to the selection of therapist variables; therefore only information on age, gender and training status are recorded. With respect to treatment variables, the current treatment status (ongoing, completed or discontinued therapy), number of sessions and type of psychotherapeutic procedure are stored.

(6) Process to expand the dataset in the future - Since the success of KODAP essentially depends on smooth and reliable data collection and combination, only a manageable number of patient, therapist and therapy variables should be transmitted at the start of the project. However, a particular strength of a large-scale collaborative project is that it allows the investigation of rare disorders or therapy phenomena as well as new survey instruments. An extension of the initial data set is therefore planned for the future. It is relatively easy to extend the data set with instruments or variables, of which we know from Study 1 (Hoyer et al., 2015) that the majority of clinics already use them (e.g., SPS, SIAS, SOMS 2, EDI 2). In the long term, the survey can be expanded by follow-up data through multiple measurements across the course of therapy as well as freely available psychometric instruments. Similar to the British Improving Access to Psychological Therapies (IAPT) (Clark, 2018) program, KODAP will also serve to develop and establish public domain instruments. In addition, all participating project partners are free to propose additional time-limited research questions. If an additional variable that is relevant for many patients is specifically collected over a clearly defined period (e.g., 3 or 6 months) in all clinics, large, clinically well-documented samples can be obtained in a very short time. 
(7) Data protection and ethical approval - As the variables to be collected in the clinic include sensitive treatment and health data special attention had to be given to data protection aspects in the run-up to the project as discussed in section (5) above. With regard to data transmission, various technical implementations were examined by the steering group. The solution needed to ensure longitudinal data collection, secure data transmission and storage, easy application by the clinic and low maintenance in the coordination center. In order not to delay the start of the project due to costly and time-consuming technology, we decided to merge the data records into one SPSS data record. A corresponding SPSS template (for adults or children and adolescents) is provided to all participating clinics at the start of the project, which will be sent back to the coordination center on encrypted data carriers at the end of the first project year. The data are stored in secured form on the server of the coordination center. In order to ensure that the transfer of patient data in KODAP is ethically acceptable, an informed consent form was developed, which has to be signed by the patients before the start of treatment (in German language, available from the first author on request). Before the start of the project, the ethics committee of the Faculty of Psychology at Ruhr University Bochum approved the project. The clinics are, however, free to additionally secure their participation in the project by submitting their own applications to their local ethics committees.

(8) Planning of the final feasibility studies - The first transmission of data, which form the basis for longitudinal analyses over several years, was planned to take place between the clinics and the coordination center in January 2019. At this point, the core data of those patients whose treatment started in 2018 were to be transmitted. Before this, however, it was planned to pilot the processes necessary for data preparation, transmission and aggregation at the cooperation partners and the coordination center. For this purpose, the clinics that joined the project by September 2017 provided the patients' core data sets from 2016 for two final (the third and fourth) feasibility studies. The benefits of these feasibility studies go far beyond the mere optimization of the project processes as descriptive statistics of patient data (e.g., distribution of diagnoses, age structure, type and number of co-morbidities and severity of treated disorders) are not yet available for German psychotherapy clinics.

\section{Study 3 (Velten et al., 2018)}

\section{Method}

As of June 2018, 32 clinics from 15 locations had joined the KODAP project (26 for adults and 6 for children and adolescents). These were invited to contribute the initial core set for adult patients (see Table 3). All patients treated in the participating clinics in 2016 as well as their therapists were to be included, no other inclusion or exclusion criteria applied. A total of 16 clinics for adults were able to provide data sets (Velten et al., 2018). 
Reasons for non-participation were the lack of data due to the recent establishment of clinics and the missing approval by ethics committees for the transmission of data from 2016 because of a lack of coordinated consent forms. The participating clinics checked their internal data for completeness and compatibility and assessed the time and personnel required to process and transmit the data. In the coordination center data quality and ease of data transmission were tested. Faulty data points were reported back to the clinics. In addition, study protocols with precise information on all variables were sent to the clinics, which were to be returned to the coordination center together with the quantitative data set. A qualitative evaluation of the study protocols was used to check the variables for conclusiveness and to identify difficulties in data collection.

In order to prevent possible personal identification, some variables (e.g., occupation, exact time of treatment, transgenderness) were not collected. ICD-10 F diagnoses (Dilling, Mombour, Schmidt, \& Weltgesundheitsorganisation, 2005; World Health Organization, 1993) at the beginning of treatment were recorded separately for the initial or index diagnosis (defined as the main reason for presentation) and for additional diagnoses. Reported diagnoses had to be derived from a standardized diagnostic tool or a structured interview according to ICD-10, DSM-IV or DSM-5. In addition to the patient, therapist, and therapy variables listed in Table 3, the average number of patients treated during the study period was computed.

\section{Results}

Of the 26 KODAP adult clinics, 16 clinics (61.5\%) from ten locations (Humboldt-Universität zu Berlin, Freie Universität Berlin, Bochum, Dresden, Greifswald, Hamburg, Landau, Mainz, Trier, Osnabrück) provided data on 4504 individuals treated in 2016 (start of treatment could have been in 2016 or earlier). The number of records transmitted per clinic ranged from 24 to 756 . The completeness and quality of the data (e.g. with regard to the coding of the response options) were checked in the clinics. With the support of the coordination center, all clinics were able to adapt their internal data collection in such a way that all defined variables for the future longitudinal study could be transmitted in an adequate form. All participating clinics were able to provide the time and personnel resources needed for the preparation and transfer of the data records. All clinics transmitted the data sets to the coordination center in compliance with data protection regulations (Velten et al., 2017).

Patient sociodemographic - The majority of the persons treated (mean age $=37.87$; $S D=13.47$; Range $=15-86$ years $)$ were female $(n=2937,65.3 \%)$ and currently in a partnership ( $n=2383,67.5 \%)$. Marital status was reported as $49.4 \%(n=1777)$ single, $29.4 \%(n=1058)$ married and 9.2\% $(n=332)$ divorced. The highest school degree attained was the German "Abitur” (equivalent to A-level or International Baccalaureate Diploma) for $48.2 \%$ ( $n=1518)$, intermediate school certificate (German "Mittlere Reife") for $29.4 \%$ 
( $n=926)$ and basic school certificate (German "Hauptschulabschluss") for 18.1\% $(n=570)$. At the start of treatment, $68.7 \%(n=803)$ of the patients were able to work. In addition to the $18.6 \%(n=217)$ disabled patients, $5.5 \%(n=64)$ received a retirement pension and $3.1 \%$ $(n=36)$ an invalidity pension.

Patient diagnoses - Nearly all clinics stated that the diagnosis at the beginning of treatment was confirmed by structured or standardized interview procedures. Only one outpatient clinic reported that an interview was not always used. A total of 7947 diagnoses were assigned to 4266 patients. Neurotic, stress and somatoform disorders (F4) were the most common category, followed by affective disorders (F3). A recurrent depressive disorder, currently a moderate episode (F33.1), was diagnosed 844 times, making it the most common disorder. With 651 and 539 assigned diagnoses, social phobia and the moderate depressive episode were the second and third most common disorders. Personality and behavioral disorders were diagnosed a total of 563 times. At least one personality disorder (F60 or F61) was present in 10.8\% of all patients. The distribution of index diagnoses, which were defined as treatment causes in this study, differed from that of the overall distribution of all diagnoses assigned. Although F4 diagnoses were the most frequently assigned, affective disorders (F3) were by far the most frequent index diagnoses with $39.4 \%(n=1682)$. Phobias (F40.-) and other anxiety disorders (F41.-) accounted for $14.2 \%(n=607)$ of the initial diagnoses. Also frequently given were index diagnoses in the area of somatoform disorders (F45.-) with $5.5 \%(n=233)$, post-traumatic stress disorder (F43.1) with 4.5\% $(n=190)$, adaptation disorders (F43.2) with $4.5 \%(n=$ 190), eating disorders (F50.-) with 4.4\% $(n=186)$ and emotionally unstable personality disorder: borderline type (F60.31) with 2.6\% $(n=113)$. However, patients with bipolar affective disorders $(n=42 ; 0.9 \%)$, schizophrenia $(n=44 ; 1.0 \%)$ and sexual dysfunction $(n=8 ; 0.2 \%)$ as index diagnoses were rarely treated. The average number of diagnoses given was $1.84(S D=0.99$, range $=0-7)$. Thus, multimorbidity was found in the majority of cases. $43.1 \%(n=1865)$ had only one diagnosis, $33.4 \%(n=1448)$ had two and $21.6 \%$ $(n=942)$ had three or more. Only $1.7 \%(n=74)$ had no diagnosis at the start of treatment or no diagnosis was recorded in the system. The most frequent comorbidity pattern was the co-occurrence of affective disorders (F3) and neurotic, stress and somatoform disorders (F4). For example, 581 patients (13.7\%) with F4 index diagnosis had an additional F3 diagnosis. The reverse pattern, F3 as first diagnosis and F4 as second and/or third diagnosis, applied to 546 patients (12.8\%). Figure 1 shows the proportion of patients treated in research and training clinics by index diagnosis (ICD-10). 


\section{Figure 1}

Proportion of Patients Treated in Research and Training Clinics by Index Diagnosis (ICD-10)
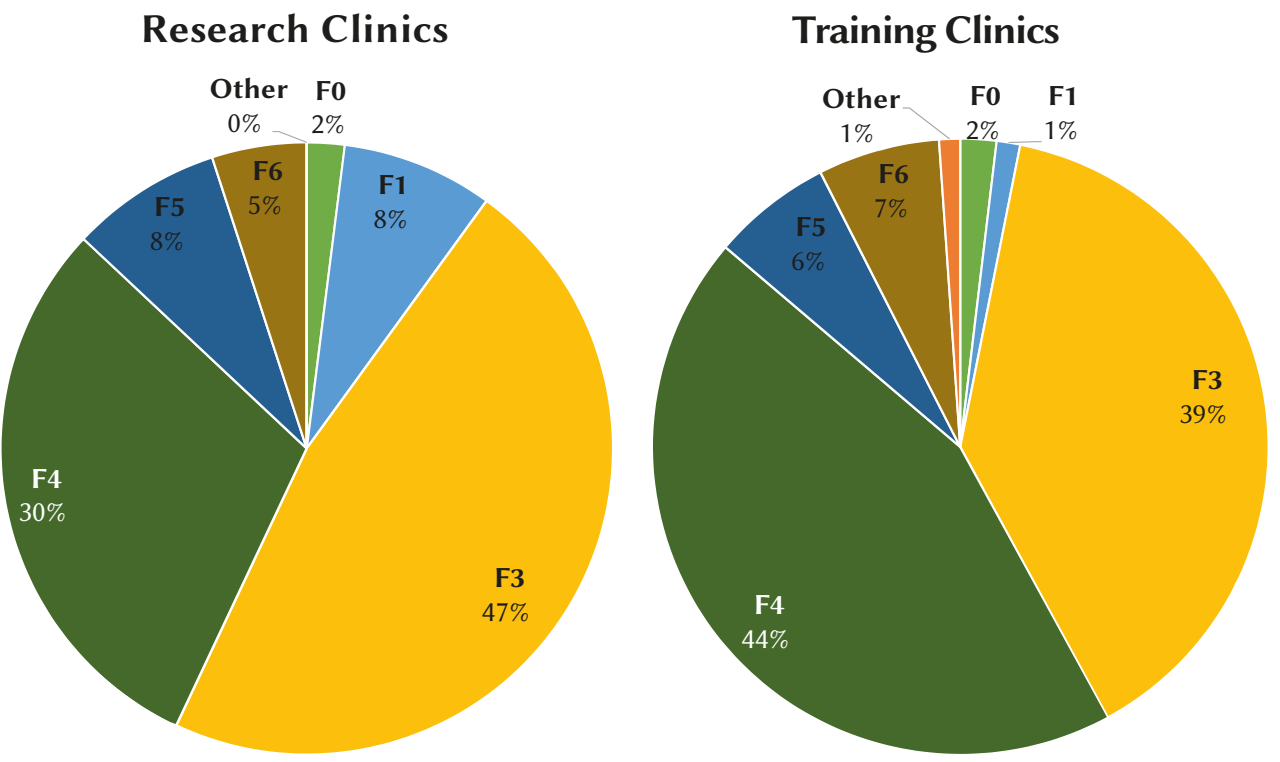

- F0: Mental and behavioural disorders due to psychoactive substance use

- F1: Schizophrenia, schizotypal and delusional disorders

F3: Mood (affective) disorders

- F4: Neurotic, stress-related and somatoform disorders

- F5: Behavioural syndroms associated with physiological disturbances and physical factors

- F6: Disorders of adult personality and behaviour

Other

Table S1 in the Supplementary Materials shows the 50 most frequently assigned diagnoses, broken down by main disorder categories. Table S2 in the Supplementary Materials shows the 50 most frequently assigned index diagnoses, which were defined as treatment causes in this study. Table S3 in the Supplementary Materials shows the most frequent diagnostic combinations or comorbidity patterns after ICD-10-F disorder sections.

Patient psychopathological symptoms - Four clinics ( $n=844$ patients) provided data on the severity of the impairment at the start of therapy as assessed by the CGI. According to their therapists, $0.1 \%$ of the patients were not ill at all, $1.1 \%$ were borderline cases of mental disorder, $5.9 \%$ were only mildly ill, $28.9 \%$ were moderately ill, $49.8 \%$ were markedly ill, $12.1 \%$ were severely ill and $0.7 \%$ were among the most extremely ill patients. Table 4 shows the BSI and BDI values at the start of therapy. At the start of treatment, clinically relevant elevated BSI values (GSI > 0.61) were present in $76 \%(n=$ 
2823), clinically significant BDI values (total values in BDI-I or BDI-II $>14$ ) in $70 \%(n=$ 2298 ) of the treated persons. Severe depression symptoms (total values in BDI-I or BDI-II > 29) were reported by $24.3 \%(n=797)$ of patients at the start of treatment.

Table 4

Level of Patients' Psychopathological Symptoms at the Beginning of Treatment

\begin{tabular}{lccc}
\hline Instrument & $\boldsymbol{n}$ & $\boldsymbol{M}$ & $\boldsymbol{S D}$ \\
\hline Brief Symptom Inventory $^{\mathrm{a}}$, BSI & 3753 & 0.89 & 0.77 \\
$\quad$ Somatization & 3757 & 1.47 & 0.87 \\
Obsession-Compulsion $_{\text {Interpersonal Sensitivity }}$ & 3758 & 1.44 & 1.00 \\
Depression & 3760 & 1.36 & 0.93 \\
Anxiety & 3754 & 1.14 & 0.83 \\
Hostility & 3760 & 0.96 & 0.76 \\
Phobic anxiety & 3756 & 0.85 & 0.88 \\
Paranoid ideation & 3760 & 1.10 & 0.88 \\
$\quad$ Psychoticism & 3756 & 0.92 & 0.77 \\
\hline Beck Depression Inventory ${ }^{\mathbf{b}}$, BDI & 3763 & 1.12 & 0.67 \\
BDI-I & & & \\
BDI-II & 642 & 18.47 & 10.10 \\
\hline
\end{tabular}

${ }^{\mathrm{a} D e r o g a t i s ~ \& ~ S p e n c e r, ~ 1993 ; ~ F r a n k e, ~ 1997 . ~}{ }^{\mathrm{b}}$ Hautzinger et al., 2000, 2009.

Psychotherapeutic treatments - In accordance with German psychotherapy regulations, a limited number of sessions are reserved for diagnostic procedures including case history and indicative decisions (so called probatory sessions). An average of 4.77 probatory sessions $(S D=0.85$; range $=0-13$ ) were performed. An outlier analysis showed only $1.5 \%$ of the treatments involved more than five probatory sessions. The number of regular therapy sessions after the probatory sessions was $35.01(S D=22.28$, range $=$ $0-117)$. While $42.7 \%(n=1371)$ of the therapies were terminated consensually by patient and therapist (mean duration 43.09 therapy sessions, $S D=17.09), 23.3 \%(n=748)$ were still ongoing at the time of data retrieval and $32.9 \%(n=1057)$ of patients had dropped out of treatment (mean duration 23.8 sessions, $S D=22.04$ ). In all cases, cognitive behavior therapy was used as therapeutic procedure. In the vast majority, only individual therapy sessions took place $(90.9 \%, n=2683)$, combined individual and group therapy were applied in $9.0 \%(n=284)$ of the treatments.

Therapists - A total of 675 persons (mean age $=30.91$ years, $S D=5.82$, range $=$ 22-58) were involved as therapists. Most therapists were female $(n=502,83.3 \%)$ and the majority ( $n=427,70.6 \%$ ) in advanced psychotherapy training (not licensed yet). On average, therapists treated 6.67 patients $(S D=5.75$, range $=1-54)$ during the study period. 
An average of $5.19(S D=6.94$, range $=1-43)$ patients per therapist were treated in the research clinics and $6.80(S D=5.29$, range $=1-54)$ patients per therapist in the training clinics. An outlier analysis showed that $95 \%$ of therapists were responsible for less than 17 patients.

\section{Study 4 (In-Albon et al., 2019)}

\section{Method}

This study characterized the patient population treated in 2016 in seven university outpatient psychotherapy clinics for children and adolescents (In-Albon et al., 2019). These submitted the initial core data set for children and adolescent patients (see Table 3). Completeness and quality of the data were checked in the clinics as well as in the coordination center as described in Study 3. Descriptive data on the diagnoses and comorbidity patterns of the patient population as well as sociodemographic information of their parents and therapists were analyzed. For the CBCL/6-18R and YSR/11-18R, $t$-values adapted for age and gender for a total, an externalizing and an internalizing score are reported.

\section{Results}

Study 4 characterized the patient population treated in 2016 in seven university outpatient psychotherapy clinics for children and adolescents. For the year 2016, data from 568 children and adolescents between 3 and 20 years of age $(M=11.89, S D=3.68 ; 46.6 \%$ female) were available. The most frequent diagnoses were anxiety disorders (F40, F41, F93; $n=317,35.30 \%$ ) followed by attention-deficit hyperactivity disorders and conduct disorders (F90, F91, F92; $n=195,21.71 \%$ ). In $45.6 \%$ of the patients, there was at least one additional comorbid diagnosis. The mean $t$-value of the CBCL/6-18R (mother reports) was $67.60(S D=9.94)$ for the total score, $67.03(S D=10.70)$ for internalizing problems, and $61.84(S D=12.01)$ for externalizing problems. The mean $t$-value of the YSR/11-18R was $61.35(S D=10.23)$ for the total score, $63.43(S D=12.75)$ for internalizing problems, and $54.88(S D=9.53)$ for externalizing problems. All of these are above the clinical cut-off ( $t>60$; based on German norms; Döpfner et al., 2014). Therapist CGI severity scores classified the vast majority of patients as mentally ill ( $15.1 \%$ mildly, $46.6 \%$ moderately, $28.8 \%$ markedly, and 5.5\% severely) and only few patients as not at all (1.4\%) or borderline mentally ill $(2.7 \%)$. Of the 126 therapists ( $83.1 \%$ female, mean 29.76 years, $S D=5.04)$, the majority (78.9\%) were still in psychotherapy training (not licensed yet). Each therapist was responsible for a mean of 4.51 patients (range 1-13). Cognitive behavior therapy was used for all patients, and almost all treatments (99.3\%) were conducted in an individual setting (combination of individual and group setting in $0.8 \%$ ). An average of 6.93 probatory sessions $(S D=1.59$, range $1-13)$ were performed. Most of the treatments $(52.3 \%)$ had not yet been terminated. Overall, this study indicated the feasibility of consolidating and 
evaluating research data across university outpatient psychotherapy clinics for children and adolescents.

\section{Discussion}

While other fields of research, such as physics, astronomy and genetics, have been practicing collaborative research on a large scale for some time, their value in the field of psychotherapy and mental health has only been increasingly recognized in recent years (Margraf, 2015). With the establishment of university outpatient clinics at departments of Clinical Psychology and Psychotherapy in Germany in 1999, a unique infrastructure for research, training and clinical care became available, offering opportunities for a collaborative approach. Since 2013, a steering committee works towards a systematic coordination across clinics in order to create a nationwide research platform. This platform will allow to aggregate and analyze longitudinal treatment data for adults, children and adolescents across all participating clinics and thereby contribute to the advancement of theory, practice and dissemination of psychotherapy and mental health research.

The feasibility of large-scale coordinated research was investigated in a series of four descriptive studies. An initial survey with 100\% response rate (Study 1) in 2014 identified the most relevant features of the then 53 clinics and led to recommendations for improved integration of data collection. Already in 2014, the annual number of patients reported by the clinics surpassed 10,000 children, adolescents, and adults, with a strongly growing trend. Based on these results, we defined a catalogue of challenges facing the planned research collaboration and gave unanimously derived recommendations (Study 2). Study 3 collected data on 4,504 patients from 16 clinics treated in 2016 allowing for the first time to systematically describe patients, therapists and treatments available for collaborative research in the German psychotherapy outpatient clinic network. Finally, Study 4 analyzed data of 568 child and adolescent patients from seven clinics starting treatment 2016 providing the first description of this patient population within KODAP.

\section{Adult Patients}

Diagnoses are based on evaluated, structured or standardized interviews whose validity and reliability exceed clinical judgment and other non-standardized diagnostic procedures (Margraf et al., 2017). The most frequently treated diagnostic groups in the KODAP clinics in 2016 were neurotic, stress and somatoform disorders (F4) and affective disorders (F3), the latter also yielding the most frequent index diagnoses and cause of treatment. This is in line with previous studies of psychotherapy outpatient clinics in Germany and England (Clark, 2018; Jacobi et al., 2011; Richter et al., 2013; Victor et al., 2018). The majority of KODAP patients (55\%) had several mental disorders at the start of treatment. This is more than previously reported in non-university clinics (Victor et al., 
2018), individual university clinics (Peikert et al., 2014; Richter et al., 2013) or routine care by practicing psychotherapists (Köck, 2012). While patients with almost all diagnoses and degrees of severity are treated, severe disorders (e.g., severe depressive episode, borderline disorder, chronic pain disorders, post-traumatic stress disorder) are very frequent. In addition, a sub-sample of four clinics showed that almost two thirds of the patients were rated by their therapists as markedly, severely or extremely ill. The fact, however, that psychotic disorders accounted only for one percent of treatment reasons (34th rank) calls for an increased proportion of this patient group in outpatient training settings (Schlier et al., 2017). Further investigation of the $7 \%$ of patients labeled by their therapists as borderline or only mildly ill may help to determine whether these patients may not have been in need of psychotherapy or whether some patient characteristics (e.g., certain diagnoses or symptoms, age, gender) may result in therapists' underestimation of patient distress. While patients on average had a high level of education, a lack of comparative values prevented a direct comparison with earlier studies. The results for age and gender as well as the BSI and BDI scores show that the patient population in KODAP clinics is largely comparable to other German outpatient clinics and routine care by fully licensed behavior therapists (Jacobi et al., 2011; Köck, 2012; Lutz et al., 2013; Richter et al., 2013; Victor et al., 2018).

\section{Child and Adolescent Patients}

The most frequently assigned diagnoses were anxiety disorders and behavioral disorders. This is in line with epidemiological studies, e.g. a meta-analysis (Polanczyk et al., 2015) indicating a prevalence rate of $6.5 \%$ for anxiety disorders, $5.7 \%$ for disruptive disorders, and $3.4 \%$ for ADHD. As in the adult clinics, the diagnoses are based on validated structured clinical interviews. The results of the questionnaires CBCL/6-18R and YSR/11-18R are comparable with a clinical control group of an outpatient sample in a child and adolescent psychiatric clinic (Walter et al., 2018). The categorical and dimensional diagnostic assessments as well as the comorbidity rate of almost $50 \%$ underline the clinical severity and the breadth of the problems treated in the participating child and adolescent clinics. The age range of 3 to 20 years reflects the legal restrictions for child and adolescent psychotherapists in Germany who may treat patients up to the age of 21. In contrast to the adult patient samples where roughly two thirds of the patients were female, girls and boys were equally distributed in the child and adolescent clinics.

\section{Therapists}

The high proportion of female therapists (83\%) is comparable with that of non-university training institutes (Victor et al., 2018) and somewhat higher than for practicing fully licensed psychotherapists in Germany (74.4\%), or psychologist in the USA (73\%) (APA Center for Workspace Studies, 2015). This reflects an ongoing international trend toward 
more women entering psychotherapy training and practice (APA Center for Workspace Studies, 2015). Because most of the reported treatments took place in training clinics, the majority of the therapists were not yet fully licensed. The fact that therapists treated an average of seven patients in training clinics during the study period underlines the intensity and structure of psychotherapy training in the participating clinics. Variability in number of patients treated per therapist in our data reflects the different training models (part-time vs. full-time training).

\section{Treatments}

With an average of 43 treatment sessions for adults and 36 sessions for children and adolescents (regularly terminated therapies), the length of treatment is identical to that reported in other German outpatient clinics (Victor et al., 2018). This duration, however, is higher than internationally reported as the optimal dose for routinely delivered psychological therapies (Robinson et al., 2020). Patients dropped out in about one third of the treatments. Although this figure appears high, these values are comparable with termination rates reported in similar treatment settings (Hiller et al., 2009). In order to record the proportion of quality-relevant (e.g. low therapeutic success) in comparison to non-quality-relevant drop-outs (e.g., change of residence, low level of suffering), the reasons for early termination or non-execution of approved sessions should be systematically and uniformly documented in the future.

\section{Limitations}

Although a large number of the clinics in question have already joined the KODAP project and more than half of the current member clinics contributed data to the last two feasibility studies, it is unclear to what extent the clinics included in this study are representative of all German university outpatient clinics for psychotherapy. Causes for non-participation of KODAP clinics in this study or reasons for missing variables in the transmitted data sets were not systematically documented. A more detailed, quantitative analysis of feasibility aspects related to data processing in clinics was therefore not possible. In addition, this study did not examine the extent to which clinics differ in terms of process and structural quality. Due to ethical and data protection considerations, only a limited number of personal variables of patients and therapists can be evaluated across clinics. A detailed analysis of the influence of specific personal variables, such as occupation or place of residence, is therefore not possible. Instead, this study deliberately focuses on a description of the patient population and treatment diagnoses at the beginning of treatment. The majority of clinics use the BDI-II, while two clinics still use the BDI-I. The comparability of the pre-treatment depression values across clinics with different BDI versions is therefore limited. Since the primary focus of this study was the estimation of feasibility aspects, the clinics were free to decide whether this first data 
transmission included variables already collected at the end of therapy. The analysis of treatment outcomes is planned for the longitudinal data collection that has been ongoing since the beginning of 2018 .

\section{Opportunities and Challenges}

The network provides a distinctive, unprecedented infrastructure for research, training and clinical care in psychotherapy and mental health. Clinical research designs, field experiments, and multicentric randomized controlled trials can be implemented rapidly and with large samples (e.g., 20 clinics per condition, inclusion of 1,000-5,000 patients), hence systematically solving typical problems such as recruitment issues, the lack of standardized assessments, and replicability.

Challenges for the collaborative project include expanding the core data set (e.g., behavioral data, social and biological variables), agreeing on new questions (e.g., long-term follow-up, systematic causality testing of predictors with experimental designs), and last but not least, full-cost funding of the joint research. A transfer of the network into a national structure would be desirable; a first application for consideration in the planned future National Research Center for Mental Health has already been submitted. The proof of a successfully established patient flow and the smooth realization of the cooperation will also improve the chances of success for acquisition of further third-party funding.

\section{Conclusions}

Despite different data formats, data transfer and aggregation proved feasible. Affective, neurotic, stress, and somatoform disorders accounted for most of the diagnoses within the adult patients and anxiety and behavioral disorders within the child and adolescent patients. In both groups, comorbidity was the rule rather than the exception. Overcoming legal, methodological, and technical challenges, a common core assessment battery was developed and data collection for KODAP started in 2018. As of today, 42 clinics have joined and 30 already have provided data. The compilation of selected core data from the participating clinics makes it possible to answer important scientific and technical questions. These include but are not limited to the provision of normative data on patient, therapist, parents (for the child sample) and treatment characteristics, the interactions of such variables (e.g., success in specific subgroups, interaction of patient and therapist characteristics), treatment outcomes under routine conditions, dropout rates as well as failures and side effects in therapy, rare disorders, subgroup analyses of frequent disorders, special comorbidity patterns, specific age groups (e.g., preschool age, primary school or adolescent age; older patients) and high-powered studies for the development of new instruments and treatments. The first steps of KODAP reported here show that research collaboration across university outpatient clinics is feasible, provided that clin- 
ics invest time and effort for data collection, data checking and data transfer. Fulfilling the need for stronger cumulative and cooperative research in psychotherapy and related fields will contribute to better knowledge about mental health, a core challenge to modern societies.

Funding: Financial support was provided by unith.ev, Kinder- und Jugendlichenpsychotherapie Verhaltenstherapie e.V., the Mental Health Research and Treatment Center at Ruhr University Bochum, the Alexander von HumboldtProfessorship awarded to the first author, the departments of Clinical Child and Adolescent Psychology and Psychotherapy and Clinical Psychology and Psychotherapy at the University of Koblenz-Landau.

Competing Interests: All authors are employed by the universities listed in the affiliations. They have no conflicts of interest to declare.

Acknowledgments: The authors gratefully acknowledge the support by the participating clinic directors, therapists and patients. Christian Leson and Amelie Scupin of the Mental Health Research and Treatment Center at Ruhr University Bochum helped with data transfer and aggregation and preparation of tables and supplementary materials.

Author Contributions: Jürgen Margraf, Thomas Fydrich, Jürgen Hoyer, Tina In-Albon, Tania Lincoln, Wolfgang Lutz, Angelika Schlarb, Henning Schöttke, Ulrike Willutzki and Julia Velten jointly conceived the work described here. Julia Velten coordinated data collection and data transfer. Jürgen Margraf wrote the first draft of the manuscript. Tina In-Albon contributed the first draft of the sections on Study 4. All authors read the manuscript, gave feedback and agreed to the final version of the manuscript.

All authors except for the first, second, and last are listed in alphabetical order.

Statement of Ethics: This research complies with the guidelines for human studies and was conducted ethically in accordance with the World Medical Association Declaration of Helsinki. All patients gave their written informed consent and that the study was approved by the ethics committee of the Faculty of Psychology at Ruhr University Bochum.

Twitter Accounts: @Psychojule, @fbzrub

\section{Supplementary Materials}

The Supplementary Materials include three tables listing the diagnoses of patients in Study 3 (for access see Index of Supplementary Materials below).

\section{Index of Supplementary Materials}

Margraf, J., Hoyer, J., Fydrich, T., In-Albon, T., Lincoln, T., Lutz, W., \& Velten, J. (2021). Supplementary materials to "The cooperative revolution reaches clinical psychology and psychotherapy: An example from Germany" [Additional information]. PsychOpen. https://doi.org/10.23668/psycharchives.4559 


\section{References}

APA Center for Workspace Studies. (2015). 2005-13: Demographics of the U.S. Psychology Workforce. Retrieved from https://www.apa.org/workforce/publications/13-demographics

Balon, R. (2017). Clinical factor 2016. Psychotherapy and Psychosomatics, 86(6), 323-331. https://doi.org/10.1159/000479820

Borkovec, T. D., Echemendia, R. J., Ragusea, S. A., \& Ruiz, M. (2001). The Pennsylvania practice research network and future possibilities for clinically meaningful and scientifically rigorous psychotherapy effectiveness research. Clinical Psychology: Science and Practice, 8(2), 155-167. https://doi.org/10.1093/clipsy.8.2.155

Brailovskaia, J., Margraf, J., \& Köllner, V. (2019). Addicted to Facebook? Relationship between Facebook Addiction Disorder, duration of Facebook use and narcissism in an inpatient sample. Psychiatry Research, 273, 52-57. https://doi.org/10.1016/j.psychres.2019.01.016

Brailovskaia, J., Rohmann, E., Bierhoff, H.-W., \& Margraf, J. (2018). The brave blue world: Facebook flow and Facebook Addiction Disorder (FAD). PLoS One, 13(7), Article e0201484. https://doi.org/10.1371/journal.pone.0201484

Button, K. S., Ioannidis, J. P. A., Mokrysz, C., Nosek, B. A., Flint, J., Robinson, E. S. J., \& Munafò, M. R. (2013). Power failure: Why small sample size undermines the reliability of neuroscience. Nature Reviews Neuroscience, 14(5), 365-376. https://doi.org/10.1038/nrn3475

Camerer, C. F., Dreber, A., Holzmeister, F., Ho, T.-H., Huber, J., Johannesson, M., . . Pfeiffer, T. (2018). Evaluating the replicability of social science experiments in Nature and Science between 2010 and 2015. Nature Human Behaviour, 2(9), 637-644.

https://doi.org/10.1038/s41562-018-0399-z

Castonguay, L. G. (2011). Psychotherapy, psychopathology, research and practice: Pathways of connections and integration. Psychotherapy Research, 21(2), 125-140.

https://doi.org/10.1080/10503307.2011.563250

Chartier, C., Kline, M., McCarthy, R., Nuijten, M., Dunleavy, D. J., \& Ledgerwood, A. (2018). The cooperative revolution is making psychological science better. Association for Pychological Science: Observer, 31(10). Retrieved from

https://www.psychologicalscience.org/observer/the-cooperative-revolution-is-makingpsychological-science-better

Clark, D. M. (2018). Realizing the mass public benefit of evidence-based psychological therapies: The IAPT program. Annual Review of Clinical Psychology, 14, 159-183. https://doi.org/10.1146/annurev-clinpsy-050817-084833

Coleman, J. R. I., Lester, K. J., Roberts, S., Keers, R., Lee, S. H., De Jong, S., . . Schneider, S. (2017). Separate and combined effects of genetic variants and pre-treatment whole blood gene expression on response to exposure-based cognitive behavioural therapy for anxiety disorders. The World Journal of Biological Psychiatry, 18(3), 215-226.

https://doi.org/10.1080/15622975.2016.1208841 
Derogatis, L. R. (1992). SCL-90-R: Administration, scoring \& procedures manual-II for the (revised) version and other instruments of the psychopathology rating scale series. Towson, MD, USA: Clinical Psychometric Research.

Derogatis, L. R., \& Spencer, P. M. (1993). Brief symptom inventory: BSI. Upper Saddle River, NJ, USA: Pearson.

Dilling, H., Mombour, W., Schmidt, M. H., \& Weltgesundheitsorganisation. (2005). Internationale Klassifikation psychischer Störungen ICD-10 Kapitel V (F), klinisch-diagnostische Leitlinien. Bern, Switzerland: Hogrefe.

Döpfner, M., Plück, J., \& Kinnen, C. (2014). Deutsche Schulalter-Formen der Child Behavior Checklist von Thomas M. Achenbach. Elternfragebogen über das Verhalten von Kindern und Jugendlichen (CBCL/6-18R), Lehrerfragebogen über das Verhalten von Kindern und fugendlichen (TRF/6-18R), Fragebogen für fugendliche (YSR/11-18R) [Manual]. Göttingen, Germany: Hogrefe.

Döpfner, M., Schnabel, M., Goletz, H., \& Ollendick, T. H. (2006). Phobiefragebogen für Kinder und fugendliche (PHOKI). Göttingen, Germany: Hogrefe.

Dumas-Mallet, E., Button, K. S., Boraud, T., Gonon, F., \& Munafò, M. R. (2017). Low statistical power in biomedical science: A review of three human research domains. Royal Society Open Science, 4(2), Article 160254. https://doi.org/10.1098/rsos.160254

Ehlers, A., Margraf, J., \& Chambless, D. (2001). Fragebogen zu körperbezogenen Ängsten, Kognitionen und Vermeidung: AKV. Göttingen, Germany: Beltz Test.

European Parliament and Council. (2016). Regulation EU 2016/679 of the European Parliament and of the Council of 27 April 2016. Official fournal of the European Union. Retrieved from http://data.europa.eu/eli/reg/2016/679/oj

Fang, F. C., \& Casadevall, A. (2012a). Reforming science: Structural reforms. Infection and Immunity, 80(3), 897-901. https://doi.org/10.1128/IAI.06184-11

Fang, F. C., \& Casadevall, A. (2012b). Winner takes all. Scientific American, 307(2), 13-17. https://doi.org/10.1038/scientificamerican0812-13

Flint, J., Cuijpers, P., Horder, J., Koole, S. L., \& Munafò, M. R. (2015). Is there an excess of significant findings in published studies of psychotherapy for depression? Psychological Medicine, 45(2), 439-446. https://doi.org/10.1017/S0033291714001421

Franke, G. H. (1997). Erste Studien zur Güte des Brief Symptom Inventory (BSI). Zeitschrift für Medizinische Psychologie, 6, 159-166.

Franke, G. H., \& Derogatis, L. R. (1995). Die Symptom-Checkliste von Derogatis (SCL-90-R) Deutsche Version - Manual. Weinheim, Germany: Beltz Test.

Gloster, A. T., Wittchen, H.-U., Einsle, F., Lang, T., Helbig-Lang, S., Fydrich, T., . . A Alpers, G. W. (2011). Psychological treatment for panic disorder with agoraphobia: A randomized controlled trial to examine the role of therapist-guided exposure in situ in CBT. fournal of Consulting and Clinical Psychology, 79(3), 406-420. https://doi.org/10.1037/a0023584

Griesel, D., Wessa, M., \& Flor, H. (2006). Psychometric qualities of the German version of the Posttraumatic Diagnostic Scale (PTDS). Psychological Assessment, 18(3), 262-268. https://doi.org/10.1037/1040-3590.18.3.262 
Guy, W. (1976) Clinical Global Impressions, ECDEU Assessment Manual for Psychopharmacology, revised (DHEW Publ. No. ADM 76-338). National Institute of Mental Health, Rockville, 218-222.

Hand, I., \& Büttner-Westphal, H. (1991). Die Yale-Brown Obsessive Compulsive Scale (Y-BOCS): Ein halbstrukturiertes Interview zur Beurteilung des Schweregrades von Denk-und Handlungszwängen. Verhaltenstherapie, 1(3), 223-225. https://doi.org/10.1159/000257972

Hautzinger, M., Bailer, M., Worall, H., \& Keller, F. (2000). Beck-Depressions-Inventar (BDI). Bearbeitung der deutschen Ausgabe. Testhandbuch (3rd ed.). Bern, Switzerland: Huber.

Hautzinger, M., Keller, F., \& Kühner, C. (2009). BDI-II. Beck-Depressions-Inventar. Revision (2nd ed.). Frankfurt am Main, Germany: Pearson Assessment.

Hiller, W., Bleichhardt, G., \& Schindler, A. (2009). Evaluation von Psychotherapien aus der Perspektive von Qualitätssicherung und Qualitätsmanagement. Zeitschrift für Psychiatrie, Psychologie und Psychotherapie, 57(1), 7-22. https://doi.org/10.1024/1661-4747.57.1.7

Hiller, W., Zaudig, M., \& Mombour, W. (1997). IDCL: Internationale Diagnosen-Checklisten für DSMIV und ICD-10. Göttingen, Germany: Hogrefe.

Horowitz, L. M., Alden, L. E., Kordy, H., \& Strauß, B. (2000). Inventar zur Erfassung interpersonaler Probleme (IIP-D): Deutsche Version. Weinheim, Germany: Beltz Test.

Hoyer, J., Velten, J., Benecke, C., Berking, M., Heinrichs, N., In-Albon, T., . . Margraf, J. (2015). Koordination der Forschung an Hochschulambulanzen für Psychotherapie: Status quo und Agenda. Zeitschrift für Klinische Psychologie und Psychotherapie, 44(2), 80-87.

https://doi.org/10.1026/1616-3443/a000308

Hoyer, J., Wiltink, J., Hiller, W., Miller, R., Salzer, S., Sarnowsky, S., . . Leibing, E. (2016). Baseline patient characteristics predicting outcome and attrition in cognitive therapy for social phobia: Results from a large multicentre trial. Clinical Psychology \& Psychotherapy, 23(1), 35-46. https://doi.org/10.1002/cpp.1936

In-Albon, T., Christiansen, H., Imort, S., Krause, K., Schlarb, A., Schneider, S., . . Velten, J. (2019). Forschungsnetzwerk KODAP: Pilotdaten zur Inanspruchnahmepopulation universitärer Psychotherapie-Ambulanzen für Kinder und Jugendliche. Zeitschrift für Klinische Psychologie und Psychotherapie, 48(1), 40-50. https://doi.org/10.1026/1616-3443/a000528

Ioannidis, J. P. A. (2005). Why most published research findings are false. PLoS Medicine, 2(8), Article e124. https://doi.org/10.1371/journal.pmed.0020124

Ioannidis, J. P. A. (2016). Why most clinical research is not useful. PLoS Medicine, 13(6), Article e1002049. https://doi.org/10.1371/journal.pmed.1002049

Jacobi, F., Uhmann, S., \& Hoyer, J. (2011). Wie häufig ist therapeutischer Misserfolg in der ambulanten Psychotherapie? Ergebnisse aus einer verhaltenstherapeutischen Hochschulambulanz. Zeitschrift für Klinische Psychologie und Psychotherapie, 40(4), 246-256. https://doi.org/10.1026/1616-3443/a000122

Kadouri, A., Corruble, E., \& Falissard, B. (2007). The improved Clinical Global Impression Scale (iCGI): Development and validation in depression. BMC Psychiatry, 7(1), Article 7. https://doi.org/10.1186/1471-244X-7-7 
Kirsch, I., Moore, T. J., Scoboria, A., \& Nicholls, S. S. (2002). The emperor's new drugs: An analysis of antidepressant medication data submitted to the US Food and Drug Administration. Prevention \& Treatment, 5(1), Article 23. https://doi.org/10.1037/1522-3736.5.1.523a

Köck, K. (2012). Komorbidität in der ambulanten Psychotherapie (Unpublished doctoral dissertation). Trier University, Trier, Germany.

Lutz, W., Ehrlich, T., Rubel, J., Hallwachs, N., Röttger, M.-A., Jorasz, C., . . Tschitsaz-Stucki, A. (2013). The ups and downs of psychotherapy: Sudden gains and sudden losses identified with session reports. Psychotherapy Research, 23(1), 14-24.

https://doi.org/10.1080/10503307.2012.693837

Lutz, W., Schürch, E., Stulz, N., Böhnke, J. R., Schöttke, H., Rogner, J., \& Wiedl, K. H. (2009). Entwicklung und psychometrische Kennwerte des Fragebogens zur Evaluation von Psychotherapieverläufen (FEP). Diagnostica, 55(2), 106-116. https://doi.org/10.1026/0012-1924.55.2.106

Maercker, A., \& Schützwohl, M. (1998). Erfassung von psychischen Belastungsfolgen: Die Impact of Event Skala-revidierte Version (IES-R). Diagnostica, 44, 130-141.

Margraf, J. (2015). Zur Lage der Psychologie. Psychologische Rundschau, 66, 1-30. https://doi.org/10.1026/0033-3042/a000247

Margraf, J., Cwik, J. C., Pflug, V., \& Schneider, S. (2017). Strukturierte klinische Interviews zur Erfassung psychischer Störungen über die Lebensspanne: Gütekriterien und Weiterentwicklungen der DIPS-Verfahren [Structured clinical interviews for mental disorders across the life span: Psychometric quality and further developments of the DIPS open access interviews]. Zeitschrift für Klinische Psychologie und Psychotherapie, 46(3), 176-186. https://doi.org/10.1026/1616-3443/a000430

Mattejat, F., \& Remschmidt, H. (2006). ILK Inventar zur Erfassung der Lebensqualität bei Kindern und fugendlichen. Bern, Switzerland: Huber.

Melfsen, S., Florin, I., \& Warnke, A. (2001). SPAIK: Sozialphobie und-angstinventar für Kinder. Göttingen, Germany: Hogrefe.

Mischel, W. (2008). The toothbrush problem. Association for Psychological Science: Observer, 21(11). Retrieved from https://www.psychologicalscience.org/observer/the-toothbrush-problem

Mischel, W. (2009). Becoming a cumulative science. Association for Psychological Science: Observer, 22(1). Retrieved from https://www.psychologicalscience.org/observer/becoming-a-cumulative-science

Nosek, B. A., Spies, J. R., \& Motyl, M. (2012). Scientific utopia: II. Restructuring incentives and practices to promote truth over publishability. Perspectives on Psychological Science, 7(6), 615-631. https://doi.org/10.1177/1745691612459058

Open Science Collaboration. (2015). Estimating the reproducibility of psychological science. Science, 349(6251), Article aac4716. https://doi.org/10.1126/science.aac4716

Pashler, H., \& Wagenmakers, E. (2012). Editors' introduction to the special section on replicability in psychological science: A crisis of confidence? Perspectives on Psychological Science, 7(6), 528-530. https://doi.org/10.1177/1745691612465253 
Paul, T., \& Thiel, A. (2004). Eating Disorder Inventory-2. Deutsche Version. Göttingen, Germany: Hogrefe.

Peikert, G., Baum, A., Barchmann, D., Schröder, D., \& Kropp, P. (2014). Wie effektiv sind Ausbildungstherapien? Vergleichsstudie zur Effektivität von Ausbildungs- und Regeltherapien. Verhaltenstherapie, 24(4), 272-279. https://doi.org/10.1159/000369270

Polanczyk, G. V., Salum, G. A., Sugaya, L. S., Caye, A., \& Rohde, L. A. (2015). Annual research review: A meta-analysis of the worldwide prevalence of mental disorders in children and adolescents. Journal of Child Psychology and Psychiatry, and Allied Disciplines, 56(3), 345-365. https://doi.org/10.1111/jcpp.12381

Pudel, V., \& Westenhöfer, J. (1989). Handanweisung, Fragebogen zum Essverhalten (FEV). Göttingen, Germany: Hogrefe.

Rayner, C., Coleman, J. R. I., Purves, K. L., Hodsoll, J., Goldsmith, K., Alpers, G. W., . . Eley, T. C. (2019). A genome-wide association meta-analysis of prognostic outcomes following cognitive behavioural therapy in individuals with anxiety and depressive disorders. Translational Psychiatry, 9(1), Article 150. https://doi.org/10.1038/s41398-019-0481-y

Richter, S., Gutt, F., \& Hamm, A. O. (2013). Evaluation ambulanter Psychotherapien in einer Hochschulambulanz. Verhaltenstherapie \& Verhaltensmedizin, 34(1), 3-21.

Rief, W., Hiller, W., \& Heuser, J. (1997). SOMS-Das Screening für Somatoforme Störungen: Manual zum Fragebogen. Bern, Switzerland: Huber.

Roberts, S., Keers, R., Breen, G., Coleman, J. R. I., Jöhren, P., Kepa, A., . . Teismann, T. (2019). DNA methylation of FKBP5 and response to exposure-based psychological therapy. American fournal of Medical Genetics: Part B. Neuropsychiatric Genetics, 180(2), 150-158.

https://doi.org/10.1002/ajmg.b.32650

Roberts, S., Wong, C. C. Y., Breen, G., Coleman, J. R. I., De Jong, S., Jöhren, P., . . Margraf, J. (2017). Genome-wide expression and response to exposure-based psychological therapy for anxiety disorders. Translational Psychiatry, 7(8), Article e1219. https://doi.org/10.1038/tp.2017.177

Robinson, L., Delgadillo, J., \& Kellett, S. (2020). The dose-response effect in routinely delivered psychological therapies: A systematic review. Psychotherapy Research, 30(1), 79-96. https://doi.org/10.1080/10503307.2019.1566676

Rosenthal, R. (1979). The file drawer problem and tolerance for null results. Psychological Bulletin, 86(3), 638-641. https://doi.org/10.1037/0033-2909.86.3.638

Rossi, J. S. (1990). Statistical power of psychological research: What have we gained in 20 years? fournal of Consulting and Clinical Psychology, 58(5), 646-656. https://doi.org/10.1037/0022-006X.58.5.646

Schlier, B., Wiese, S., Frantz, I., \& Lincoln, T. M. (2017). Chancengleichheit in der ambulanten Therapie: Ein Experiment zur Bereitschaft von niedergelassenen Psychotherapeuten, Patienten mit Schizophrenie zu behandeln. Verhaltenstherapie, 27(3), 161-168. https://doi.org/10.1159/000478533 
Schneider, S., In-Albon, T., Nuendel, B., \& Margraf, J. (2013). Parental panic treatment reduces children's long-term psychopathology: A prospective longitudinal study. Psychotherapy and Psychosomatics, 82(5), 346-348. https://doi.org/10.1159/000350448

Schneider, S., \& Margraf, J. (2011). DIPS: Diagnostisches Interview bei psychischen Störungen (DIPS für DSM-IV-TR) (4th ed.). Berlin, Germany: Springer.

Schneider, S., Unnewehr, S., \& Margraf, J. (2009). Diagnostisches Interview bei psychischen Störungen im Kindes- und Jugendalter. Kinder-DIPS. Berlin, Germany: Springer.

Sierra, M., \& David, A. S. (2011). Depersonalization: A selective impairment of self-awareness. Consciousness and Cognition, 20(1), 99-108. https://doi.org/10.1016/j.concog.2010.10.018

Simmons, J. P., Nelson, L. D., \& Simonsohn, U. (2011). False-positive psychology: Undisclosed flexibility in data collection and analysis allows presenting anything as significant. Psychological Science, 22(11), 1359-1366. https://doi.org/10.1177/0956797611417632

Spellman, B. A. (2015). A short (personal) future history of revolution 2.0. Perspectives on Psychological Science, 10(6), 886-899. https://doi.org/10.1177/1745691615609918

Stangier, U., Heidenreich, T., Berardi, A., Golbs, U., \& Hoyer, J. (1999). Die Erfassung sozialer Phobie durch Social Interaction Anxiety Scale (SIAS) und die Social Phobia Scale (SPS). Zeitschrift für Klinische Psychologie, 28(1), 28-36. https://doi.org/10.1026//0084-5345.28.1.28

Stiensmeier-Pelster, J., Schürmann, M., \& Duda, K. (2014). DIKf-Depressions-Inventar für Kinder und fugendliche. Göttingen, Germany: Hogrefe.

Turner, E. H., Matthews, A. M., Linardatos, E., Tell, R. A., \& Rosenthal, R. (2008). Selective publication of antidepressant trials and its influence on apparent efficacy. The New England Journal of Medicine, 358(3), 252-260. https://doi.org/10.1056/NEJMsa065779

Velten, J., Bräscher, A.-K., Fehm, L., Fladung, A.-K., Fydrich, T., Heider, J., . . Hoyer, J. (2018). Behandlungsdiagnosen in universitären Ambulanzen für psychologische Psychotherapie im Jahr 2016. Zeitschrift für Klinische Psychologie und Psychotherapie, 47, 175-185. https://doi.org/10.1026/1616-3443/a000490

Velten, J., Margraf, J., Benecke, C., Berking, M., In-Albon, T., Lincoln, T., . . Hover, J. (2017). Methodenpapier zur Koordination der Datenerhebung und -auswertung an Hochschul- und Ausbildungsambulanzen für Psychotherapie (KODAP). Zeitschrift für Klinische Psychologie und Psychotherapie, 46(3), 169-175. https://doi.org/10.1026/1616-3443/a000431

Velten, J., Pantazidis, P., Benecke, A., Bräscher, A.-K., Fehm, L., Fladung, A.-K., . . Hoyer, J. (2021). Wie häufig werden Diagnosen aus dem Bereich der sexuellen Funktionsstörungen an deutschen Hochschulambulanzen für Psychotherapie an psychologischen Instituten vergeben? Zeitschrift für Sexualforschung, 34, 1-10.

Victor, P., Dresenkamp, A., Haag, E., Merod, R., Ruggaber, G., Sauer, K., . . Willutzki, U. (2018). Ausbildungsforschung in Ausbildungsinstituten der Deutschen Gesellschaft für Verhaltenstherapie. Psychotherapeut, 63(1), 62-67. https://doi.org/10.1007/s00278-017-0225-5

Walter, D., Dachs, L., Faber, M., Goletz, H., Goertz-Dorten, A., Hautmann, C., . . MetternichKaizman, T. W. (2018). Effectiveness of outpatient cognitive-behavioral therapy for adolescents under routine care conditions on behavioral and emotional problems rated by parents and 
patients: An observational study. European Child \& Adolescent Psychiatry, 27(1), 65-77. https://doi.org/10.1007/s00787-017-1021-z

Wannemüller, A., Moser, D., Kumsta, R., Jöhren, H.-P., Adolph, D., \& Margraf, J. (2018a). Mechanisms, genes and treatment: Experimental fear conditioning, the serotonin transporter gene, and the outcome of a highly standardized exposure-based fear treatment. Behaviour Research and Therapy, 107, 117-126. https://doi.org/10.1016/j.brat.2018.06.003

Wannemüller, A., Moser, D., Kumsta, R., Jöhren, H.-P., \& Margraf, J. (2018b). The return of fear: Variation of the serotonin transporter gene predicts outcome of a highly standardized exposure-based one-session fear treatment. Psychotherapy and Psychosomatics, 87(2), 95-104. https://doi.org/10.1159/000486100

Wieczerkowski, W., Nickel, H., Janowski, A., Fittkau, B., \& Rauer, W. (1981). Angstfragebogen für Schüler-Handanweisung. Braunschweig, Germany: Westermann.

Wittchen, H.-U., Wunderlich, U., Gruschwitz, S., \& Zaudig, M. (1997). SKID I. Strukturiertes Klinisches Interview für DSM-IV. Achse I: Psychische Störungen. Interviewheft und Beurteilungsheft. Eine deutschsprachige, erweiterte Bearb. d. amerikanischen Originalversion des SKID I. Göttingen, Germany: Hogrefe.

Wolf, M., Limberger, M. F., Kleindienst, N., Stieglitz, R.-D., Domsalla, M., Philipsen, A., . . Bohus, M. (2009). Kurzversion der Borderline-Symptom-Liste (BSL-23): Entwicklung und Überprüfung der psychometrischen Eigenschaften. Psychotherapie, Psychosomatik, Medizinische Psychologie, 59(8), 321-324. https://doi.org/10.1055/s-0028-1104598

Zaworka, W., Hand, I., Jauernig, G., \& Lünenschloß, K. (2003). Hamburger Zwangsinventar. Weinheim, Germany: Beltz.

Ziem, M., \& Hoyer, J. (2020). Modest, yet progressive: Effective therapists tend to rate therapeutic change less positively than their patients. Psychotherapy Research, 30(4), 433-446. https://doi.org/10.1080/10503307.2019.1631502

World Health Organization. (1993). The ICD-10 classification of mental and behavioural disorders: Diagnostic criteria for research. Retrieved from https://apps.who.int/iris/handle/10665/37108

\section{EACLIPT}

Clinical Psychology in Europe (CPE) is the official journal of the European Association of Clinical Psychology and Psychological Treatment (EACLIPT).

leibniz-psychology.org

PsychOpen GOLD is a publishing service by Leibniz Institute for Psychology (ZPID), Germany. 